\title{
Research on Supply Chain in Marketing Performance Evaluation of Enterprise
}

\author{
Yuanhui Huang ${ }^{1, a}$ \\ ${ }^{1}$ Guangxi Technological College of Machinery and Electricity, China \\ a649402630@qq.com
}

Keywords: Supply chain, Marketing performance,Evaluation system.

\begin{abstract}
Marketing is a series of market-related business activities in the business in a changing market environment and it is to adapt, to stimulate and satisfy consumer demand. It is not only important for enterprise business activities, but also the important basic business functions. On the one hand, companies can understand the market through marketing of consumer demand, contact a close relationship with target consumers, businesses and the market and to better meet the market needs of consumers; on the other hand, corporate prove product development through market, expanding demand and increase sales through marketing advertising, marketing and so on, so that improve consumer acceptance of new products, new technologies, and tap the potential demand, expanding the real needs and achieve business targets.
\end{abstract}

\section{Introduction}

For the current marketing studies have generally focused on the target market analysis and marketing strategy formulation and selection, and the overall performance of the actual implementation of the marketing strategy has generated less attention, even though there are some studies, are also fragmented, simply from a few financial indicators whether the program objectives to evaluation [1]. For marketing, supply chain performance measurement system and even fewer for the marketing supply chain performance measurement system can serve as a marketing decision, accurate, scientific evaluation of the performance of the supply chain, marketing, there is a need for a comprehensive evaluation index system, use appropriate models and methods for integrated supply chain performance marketing for evaluation [2]. In order to adopt a comprehensive evaluation of marketing performance, to take advantage of past marketing decisions beneficial to the letter. Therefore, the study of marketing supply chain system performance is very necessary both for marketing and for the entire supply chain system.

\section{The Supply Chain Model}

All organizations can be seen as an integral part or several of the supply chain. Whether a company is carried out for the final consumer sales, service, manufacturing products or extraction of raw materials, they are invariably reflected in the supply chain. In recent years, various companies first focus on its internal management as well as directly to customers, and supply chain network to other companies little attention [3]. But the globalization of markets and technologies in the following three aspects of the development, supply chain management has re-attracted the attention of managers.

(1) Information revolution occurred;

(2) Customer needs caused a global competition in production, service costs, quality, delivery, technology and production cycles in the field;

(3) The emergence of new organizational forms in relationship.

Each of these developments, have accelerated the process of integration of the supply chain. Model 1 establishment figure illustrates the essence of supply chain management, and the use of the process of integration of these developments. 


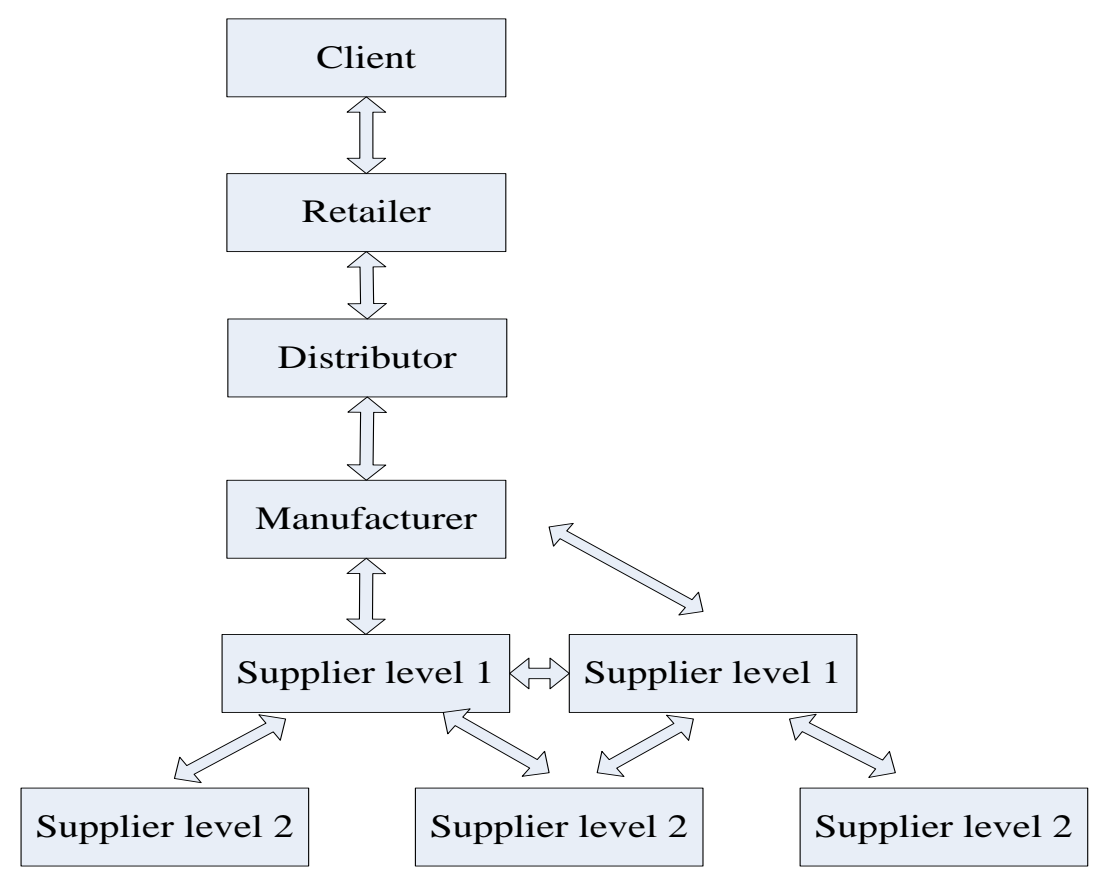

Fig. 1 The nature of the supply chain

\section{The Key Elements Analysis of Performance Measurement System Model in Supply Chain}

The Research on Evaluation Range of Evaluation Model.Marketing research scope of supply chain performance measurement system includes not only the overall marketing performance measurement of supply chain systems, but also includes various corporate marketing performance measurements [4]. However, in the supply chain system determines the relative independence of each of the various business enterprises is still relatively independent stakeholders still have to carry out their marketing performance measurement, so the scope of the study of supply chain marketing performance measurement system should not contain all enterprises marketing performance measurement, and should be from the perspective of the overall optimization of the supply chain system for marketing performance evaluation.

Currently, there is no unified supply chain system to define the concept of marketing performance measurement evaluation of its scope and content [5]. According to the characteristics of supply chain management, supply chain systems, although the pursuit of enterprises optimize the overall benefits, but companies are more concerned about building their core competencies, which remains a separate legal entity. Their autonomy and not because of supply chain system and lose, but was constantly strengthened the management of all aspects of its work should be greatly improved on the original level.

Supply chain systems of each joint venture should be consistent with the overall cooperation on the basis of the interests and ensure the overall interests are not at the expense of sacrificing individual interests, but the interests of individuals must be guaranteed to be able to optimize the overall benefits of making a basic premise. Thus, each enterprise supply chain system is still the main independent interests to pursue, but the pursuit of such an interest to get some coordination within the supply chain system, in the pursuit of individual interests, to ensure optimized overall interests, to achieve a win-win new supply chain functions.

Since each enterprise supply chain system environment remain separate subjects of interest, then all enterprises must have full operational autonomy, must be their own marketing business conditions for evaluation, in order to find the problems, verify and constantly revised its management strategy.

Based on the above analysis, supply chain systems is not necessary to the cooperative enterprise marketing performance measurement into their evaluation system in the past, need only to overall supply chain performance systems for evaluation, performance measurement and should not expand the scope of the evaluation in order to avoid duplication. In addition, you can also use ad absurdum, 
why should not all corporate marketing performance measurement into the supply chain performance measurement range. Assuming the marketing supply chain performance evaluation system should include the scope of each company's marketing performance measurement work, so surely allows firms to pursue the process of internally generated local optimization of the supply chain, while ignoring the need to optimize the overall supply chain system, resulting in supply marketing chain performance evaluation system of local self- contradiction between optimization and overall optimization. More importantly, this conflict will cause enough internal supply chain coordination, overall competitiveness decline, eventually leading to the common interests of all enterprises and their interests will suffer. Thus, the supply chain system of marketing performance measurement system should not include evaluation of each enterprise supply chain performance, but only contains the overall marketing performance evaluation. Under the conditions of the supply chain system, enterprises due to focus on their core business, their marketing performance evaluation will not only add to the integrated supply chain and lost, but because of management to increase the accuracy and agility makes this work be strengthened.

The Subject of Evaluation Model. Do everything is in order to meet certain need and of course, marketing, supply chain performance measurement system is no exception. Body should first demand with supply chain performance is directly linked to marketing operations and marketing performance will directly affect the merits of their vision, interests and actions. According to stakeholder theory, is not difficult to draw the following supply chain marketing performance evaluation requirements subject:

(1) The business owner in supply chain system. Operation of the marketing supply chain performance will obviously affect the interests of their corporate owners;

(2) The management in supply chain, including supply chain system of enterprises (especially in the core business) management personnel;

(3) The clients. Marketing, supply chain performance of the system will affect the interests of customers, such as: services, technical support, etc.;

(4) The government and the public. Marketing performance and its influence on the supply chain system will allow the government and the public about its operational performance.

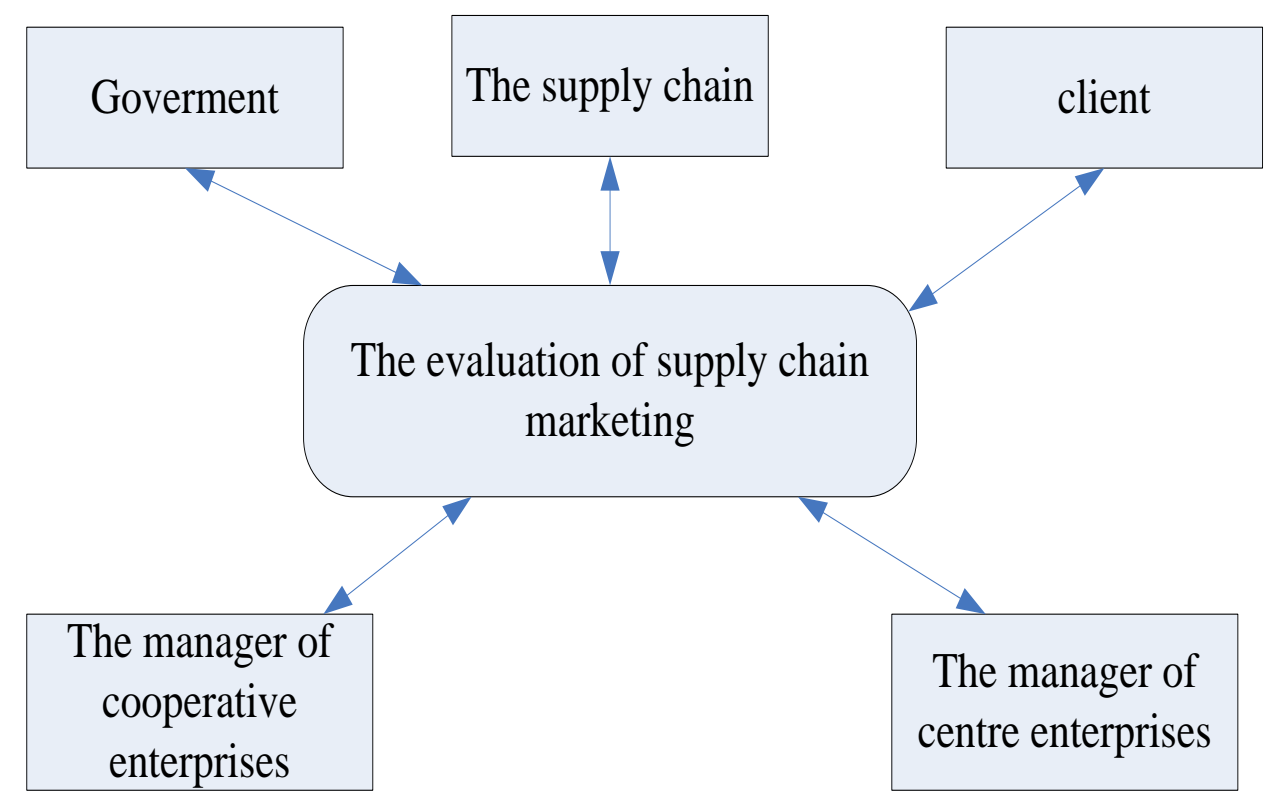

Fig. 2 Main supply and demand subject of evaluation system

The Object of Research Evaluation Model. Marketing Supply Chain Performance Evaluation System object, simply referring to what was evaluated by the evaluation of the main object is determined according to their needs, is corresponding with the main contradiction of the other. Different objects have different properties and these characteristics in the design of specific systems directly affect the establishment of the index system. Object supply chain marketing performance 
evaluation system is generally corporate marketing activities or the business itself.

\section{Conclusions}

(1) In this paper, we discussed the theory and method of application of multiple disciplines of marketing, management, accounting, and so on, integrating a variety of techniques, theories and methods of marketing. And supply chain performance measurement systems have been studied. This paper analyzes the characteristics of supply chain management system, enterprise marketing performance evaluation theories, clearly define the subject of supply chain performance evaluation system of marketing, scope, key factors.

(2) This paper analyze the supply chain system management features, combined with business marketing performance evaluation theory, specifically the need for the main marketing supply chain performance evaluation system, the basic connotation scope of the evaluation, the basic content, evaluation principles.

\section{References}

[1] William L. Waugh.Advanced Marketing Research, Vo1. 2 (2001) No. 26, p. 52-65.

[2] David R. Godschalk, Timothy Beatley, Philip Berke. David J.Brower, and Edward J.Kaiscr: Data \& Knowledge Engineering, Vo1. 1 (1999) No. 5, p. 36-52.

[3] Waugh William L and Rohn Ronald HY: Programs, Vo1. 3 (2001) No. 7, p. 106-125.

[4] Hillyard Michael J: Data \& Knowledge Engineering, Vo1. 2 (2000) No. 26, p. 52-65.

[5] Chneider Saundra K.: Public Management Marketing Situations, Vo1. 8 (1995) No.27, p. 228-235. 